\title{
Associations between physical activity, sedentary behavior, and health risk behaviors among adolescents from a city in Southern Brazil
}

\section{Associações entre atividade física, comportamento sedentário e comportamentos de} risco à saúde entre adolescentes de uma cidade do Sul do Brasil

\section{AUTHOR'S \\ Michael Pereira da Silva ${ }^{1}$ (D) \\ Fabio Eduardo Fontana ${ }^{2}$ (D) \\ Gregory J. Welk ${ }^{3}$ (D) \\ Pedro F. Saint-Maurice ${ }^{4}$ (D) \\ Edmar Roberto Fantineli ${ }^{5}$ (D) \\ Eliane Denise Araújo Bacil ${ }^{5}$ (D) \\ Wagner de Campos ${ }^{5}$ (D) \\ 1 Universidade Estadual do Centro-Oeste, Departamento de Educação Física, Guarapuava, Paraná, Brasil. \\ 2 University of Northern Iowa, School of Health, Physical Education and Leisure Services, Cedar Falls, Iowa, Estados Unidos da América. \\ 3 Iowa State University, Health and Human Performance, Ames, Iowa, Estados Unidos da América. \\ 4 National Cancer Institute, DCEG, Bethesda, Maryland, Estados Unidos da América. \\ 5 Universidade Federal do Paraná, Departamento de Educação Física, Curitiba, Paraná, Brasil.}

\section{CORRESPONDING}

Michael Pereira da Silva

prof.mpsilva@outlook.com

Rua Frei Caneca no 3159, apto. 404, Bairro

Santa Cruz, Guarapuava, Paraná, Brasil.

Zip Code: 85015-220.

DOI

$10.12820 /$ rbafs. $24 \mathrm{e} 0068$

\section{(cc) BY-NC-SA}

This work is licensed under the Creative Commons Attribution-NonCommercial-ShareAlike 4.0

International License

\begin{abstract}
This study examined the independent and combined associations of physical activity (PA) and sedentary behavior (SB) with health risk behaviors in Brazilian adolescents. Participants were 893 adolescents (454 girls) from Curitiba, Brazil. The Youth Activity Profile questionnaire evaluated PA and the Adolescent Sedentary Questionnaire evaluated SB. The Youth Risk Behavior Surveillance System (YRBS) questionnaire evaluated fruit, vegetable, alcohol, and tobacco consumption. Binary Logistic regression measured the independent and combined associations of $P A$ and $S B$ with risk behaviors. $P A$ was inversely associated with low fruit $(O R=$ 0.30; 95\%CI: $0.18-0.51)$ and vegetable consumption (OR $=0.43 ; 95 \% C I: 0.25-0.73)$, and tobacco use (OR $=0.52$; 95\%CI: 0.29-0.89). However, PA was positively associated with mild (OR $=1.54$; 95\% CI: 1.08 2.19) and excessive alcohol use (OR $=1.53 ; 95 \% C I: 1.01-2.33)$. Higher levels of $P A$ were associated with reduced risks of smoking and healthier eating patterns, but higher likelihood of alcohol consumption.
\end{abstract}

Keywords: Motor activity, Health behavior, Adolescent.

RESUMO

Este estudo examinou as associações independentes e combinadas de atividade física (AF) e do comportamento sedentário (CS) com comportamentos de risco à saúde em adolescentes brasileiros. Participaram do estudo 893 adolescentes (454 meninas) de Curitiba, Brasil. O questionário Youth Activity Profile avaliou a AF e o Questionário de atividades sedentárias dos adolescentes avaliou o CS. O questionário Youth Risk Behavior Surveillance System (YRBS) avaliou o consumo de frutas, vegetais, álcool e tabaco. A regressão logística binária avaliou as associações independentes e combinadas de $\mathrm{AF}$ e CS com comportamentos de risco. AF foi inversamente associado com baixo consumo de frutas $(\mathrm{OR}=0,30$; IC95\%: 0,18-0,51), de vegetais $(\mathrm{OR}=0,43$; IC95\%: 0,25-0,73) e uso de tabaco $(\mathrm{OR}=$ 0,52; IC95\%: 0,29-0,89). No entanto, a AF foi positivamente associada com uso moderado (OR = 1,54; IC95\%: 1,08-2,19) e uso excessivo de álcool (OR = 1,53; IC95\%: 1,01-2,33). Níveis mais altos de AF foram associados com riscos reduzidos de fumar e padrões alimentares mais saudáveis e com maior probabilidade de consumo de álcool.

Palavras-chave: Atividade motora; Comportamentos relacionados com a saúde; Adolescente.

\section{Introduction}

Adolescence is a period characterized by significant physical and psychological changes and during which several lifelong health related behaviors are adopted and established ${ }^{1}$. Youth establish values, beliefs and behaviors related to eating, smoking, alcohol drinking, and physical activity, and these interact to influence risk for obesity, diabetes and other chronic condition ${ }^{2-5}$. The high prevalence of unhealthy behaviors in adolescence is a major public health concern due to the tendency of behaviors to track into adulthood.

Physical inactivity, sedentary behaviors, smoking, 
alcohol drinking, a diet poor in fruits and vegetables are independently associated with poor health ${ }^{6}$, but the combination of these unhealthy behaviors can have an added effect on morbidity. For example, several studies have demonstrated that high PA levels and low levels of sedentary behavior (SB) are associated with lower cardiometabolic risk factors in adolescents ${ }^{7}$, and they may be affected by the same underlying factors ${ }^{8}$. Studies have also suggested that these behaviors may have a combined influence on the adoption of other health behaviors ${ }^{9,10}$. To date, few studies have examined the relationships among various health behaviors and the available evidence is equivocal. Some studies have showed that PA during adolescence is associated with a higher fruit ${ }^{11,12}$ and vegetable consumption ${ }^{11,12}$, and lower $\mathrm{SB}^{13}$, tobacco ${ }^{14,15}$, and alcohol use $\mathrm{e}^{15,16}$. Other studies have suggested a positive association between $\mathrm{PA}$ and alcohol ${ }^{10,17}$ and tobacco use ${ }^{10}$, but these same associations were not supported in other studies ${ }^{16,17}$. Higher SB, particularly screen time, has been associated with fruit and vegetable consumption ${ }^{11,17}$, alcohol $^{10,13,16,17}$ and tobacco use $\mathrm{e}^{10,16,17}$ in adolescents but interactions with PA have not been examined.

The published literature examining the association of the combined PA and SB with other health risk behaviors in adolescents is particularly understudied in developing countries such as Brazil, where prevalence of comorbidities is particularly high ${ }^{18}$. Exploring these relations in populations at high risk for adopting unhealthy behaviors is important since it can help inform policies focused on the promotion of healthy living. This study addresses this need by examining the independent and combined associations of PA and SB use with fruit and vegetable consumption and tobacco and alcohol use in Brazilian adolescents.

\section{Methods}

This study used a cross-sectional analysis of baseline data from an ongoing school-based cohort study taking place in Curitiba, Brazil. The baseline data was collected between August/2015 to December/2015. The Ethics committee from the Federal University of Paraná approved this study (protocol number: 39206214.3.3001.5539).

The initial sample included 928 adolescents aged 11 to 17 years old from public schools in Curitiba, Brazil. We used a stratified random sampling method to select 16 schools out of the 9 school districts available. From the 16 public schools contacted, 14 agreed to partici- pate. Each school contributed with 4 to 6 classrooms within grades 6 th to 12 th. We invited all students from these classrooms to participate in the study. All the participants provided signed informed consents and assent forms. Sample weights were applied to ensure proper representation of the different school districts in the sample of participants.

A demographic survey inquired about the date of birth, gender, and the period of the day participants attended school (e.g. morning or afternoon). Based on date of birth, participants were divided into $<14$ years old and $\geq 14$ years old groups.

Physical activity was assessed with the Youth Activity Profile (YAP) questionnaire, a self-administered 7 -day recall questionnaire designed for children and adolescents in $4^{\text {th }}$ to $12^{\text {th }}$ grades $^{19}$. The YAP uses a series of 10 Likert-type items that capture the relative time youth spend performing PA in different settings. An associated calibration step then enables the items to estimate the overall time spent in moderate-to-vigorous PA (MVPA) in different contexts (in school, out of the school and on weekends). Previous work showed good agreement between YAP estimates and corresponding values from objective monitoring devices ${ }^{19}$. We cross-culturally adapted the YAP to capture Brazilian adolescents PA participation and tested the YAP against an objective measure of $\mathrm{PA}$ in a subsample of adolescents ( $\mathrm{n}=143 ; 11$ to 17 years of age) founding similar associations to those reported in the original validation of the YAP ( $\mathrm{Rho}=0.36 ; \mathrm{p}<0.001)$. Therefore, we used the YAP as originally recommended ${ }^{19}$ to estimate minutes of MVPA. We then created three groups based on tertiles of MVPA calculated for each gender and setting/context.

The established YRBS survey assessed fruit and vegetable (FV) consumption. Previous work supports the validity of the YRBS items for assessing FV consumption in Brazilian adolescents ${ }^{20}$. It includes two items that measure the frequency of fruit consumption. For this study, participants consuming fruits and/or $100 \%$ natural juice less than three times per day during the past 7 days were classified as having low fruit consumption. An additional four items measured the frequency of vegetable consumption. Adolescents reporting the consumption of vegetables less than three times per day during the past 7 days were classified as low vegetable consumption.

The YRBS survey also assessed alcohol and tobacco use $^{20}$. One item assessed mild alcohol use based on the 
consumption of at least 1 drink of alcohol over the past 30 days prior to data collection. A second item assessed excessive alcohol use based on the consumption of 5 or more doses within a discrete occasion for at least one day over the past 30 days prior to data collection. A third item assessed tobacco use. Participants reporting smoking at least once in the past 30 days were classified as smokers.

The Adolescent Sedentary Activities Questionnaire assessed time spent in SB. The instrument has adequate validity for assessing SB in Brazilian adolescents ${ }^{21}$. SB consisted of the time spent watching television and movies, using computer, and playing videogames. We created three gender specific terciles based on the minutes per week spent in front of electronic screens.

Weight was measured to the nearest gram using a digital scale, and height was measured to the nearest centimeter using a portable stadiometer (W721, Wiso, Brazil). BMI was calculated as weight $(\mathrm{kg}) /$ height $\left(\mathrm{m}^{2}\right)$. Classification of BMI status followed the reference proposed by the World Health Organization for each sex and age ${ }^{22}$.

The Brazilian Association of Research Companies' Questionnaire assessed the parental educational level and income status of the family of the participants. This questionnaire has adequate validity ${ }^{23}$ and is often used to determine income status of a family based on goods available at home. We classified income status as high, mid and low. An additional single question was also used to inquire about the educational level of the parent primarily responsible for most of the family's financial earnings. We divided the parental educational level into: a) at least a college degree; b) high school or incomplete college education and; c) less than complete high school education.

The distributions of behaviors were first analyzed with descriptive statistics (means, standard deviations, and relative frequencies). Differences in the distributions between males and females were then examined using independent $\mathrm{t}$-tests for continuous variables and chi-square tests for categorically coded demographics.

A series of two logistic regression models were then run separately for each outcome to examine associations between PA and various health behaviors. Model 1 reported crude associations between PA levels and health risk behaviors. Model 2 examined the associations between PA and health risk behaviors adjusted for sex, age, BMI status, socioeconomic status, parent educational level, school period and SB time. Distri- butions of MVPA were examined for total MVPA, and MVPA accumulated in school, out of school, and during weekends.

We also conducted an additional set of analyses to examine the combined associations of MVPA and $\mathrm{SB}$ with all the remaining behaviors. We created combinations of MVPA and SB categories to generate 6 groups. We then examined main effects associated with each combined group using the low MVPA and high $\mathrm{SB}$ category as a reference group. Odds ratios (OR) and $95 \%$ confidence intervals $(95 \% \mathrm{CI})$ were computed for all models. The statistical significance was set on $p<0.05$ for the first two models and $p \leq 0.01$ for the interaction analyses to avoid type-I errors. We applied sample weights and clustered robust error type to avoid bias related to a complex sample selection. We used STATA/MP 13.0 software to perform all statistical analyses.

\section{Results}

The final sample included 893 youth. We excluded the data of 35 (3.6\%) participants from all statistical analyses due to missing information in one or more of the following variables: PA ( $n=4,0.4 \%)$, parent education level $(\mathrm{n}=17,1.8 \%)$, school period $(\mathrm{n}=5,0.5 \%)$, and BMI information $(n=9,0.9 \%)$. Additionally, we excluded data of participants missing information on the dependent variables fruit consumption $(n=16,1.7 \%)$, vegetable consumption $(\mathrm{n}=17,1.8 \%)$, mild alcohol use $(\mathrm{n}=29,3.0 \%)$, excessive alcohol use $(\mathrm{n}=30,3.2 \%)$, and tobacco use $(n=31,3.3 \%)$ from corresponding regression analyses. Excluded participants were not significantly different from included participants for any of the demographic variables measured.

The participants were on average $14.05 \pm 1.91$ years old (Table 1). Most were from mid-income families (56.5\%) and had parents with less than a complete high school education (53.0\%). Approximately 38.6\% of the participants were overweight/obese, $71.8 \%$ reported low consumption of fruits, and $78.3 \%$ low consumption of vegetables. The proportions of participants reporting excessive alcohol use was $15.6 \%$, while $6.7 \%$ reported being current smokers.

Sex comparisons showed that a higher proportion of girls were overweight $(p=0.045)$. Girls had significantly lower amounts of MVPA than boys $(p<0.001)$ as well as lower amounts of SB $(\mathrm{p}<0.001)$. Finally, girls reported higher consumption of vegetables $(p=0.035)$ and alcohol $(\mathrm{p}=0.008)$. 
Table 1 - Demographic and behavioral characteristics of the sample

\begin{tabular}{|c|c|c|c|c|c|}
\hline & $\begin{array}{c}\text { Overall } \\
(\mathrm{n}=893)\end{array}$ & $\begin{array}{c}\text { Boys } \\
(\mathrm{n}=439)\end{array}$ & $\begin{array}{c}\text { Girls } \\
(\mathrm{n}=454)\end{array}$ & \multirow[t]{2}{*}{$\mathrm{t}$} & \multirow[t]{2}{*}{$\mathrm{p}$} \\
\hline & Mean \pm SD & Mean \pm SD & Mean \pm SD & & \\
\hline Age (years) & $14.05 \pm 1.91$ & $14.11 \pm 1.96$ & $13.95 \pm 1.89$ & 1.98 & 0.09 \\
\hline \multicolumn{6}{|l|}{ Physical activity (min/week) } \\
\hline Overall MVPA & $568.61 \pm 146.09$ & $678.20 \pm 97.21$ & $462.92 \pm 100.30$ & 32.55 & $<0.001$ \\
\hline In-school MVPA & $129.24 \pm 39.38$ & $156.00 \pm 30.06$ & $103.42 \pm 28.62$ & 26.73 & $<0.001$ \\
\hline Out-of-school MVPA & $283.14 \pm 82.00$ & $329.58 \pm 69.87$ & $238.24 \pm 66.40$ & 20.01 & $<0.001$ \\
\hline Weekend MVPA & $156.34 \pm 49.89$ & $192.64 \pm 34.45$ & $121.24 \pm 35.25$ & 30.60 & $<0.001$ \\
\hline \multirow[t]{2}{*}{ Sedentary behavior (hours/week) } & $32.04 \pm 25.06$ & $37.66 \pm 28.06$ & $26.61 \pm 20.38$ & 6.72 & $<0.001$ \\
\hline & $\mathrm{n}(\%)$ & $\mathrm{n}(\%)$ & $\mathrm{n}(\%)$ & $\chi^{2}$ & $\mathrm{p}$ \\
\hline \multicolumn{6}{|l|}{ Age } \\
\hline$<$ 14-year-old & $403(45.1)$ & $195(44.4)$ & $208(45.8)$ & \multirow[t]{2}{*}{0.17} & \multirow[t]{2}{*}{0.675} \\
\hline$\geq 14$-year-old & $490(54.9)$ & $244(55.6)$ & $246(54.2)$ & & \\
\hline \multicolumn{6}{|l|}{ Income status } \\
\hline High & $205(23.0)$ & $109(24.8)$ & $96(21.1)$ & \multirow[t]{3}{*}{1.71} & \multirow[t]{3}{*}{0.424} \\
\hline Mid & $503(56.3)$ & $241(54.9)$ & $262(57.8)$ & & \\
\hline Low & $185(20.7)$ & $89(20.3)$ & $96(21.1)$ & & \\
\hline \multicolumn{6}{|l|}{ Parent educational level () } \\
\hline College degree & $172(19.3)$ & $80(18.2)$ & $92(20.3)$ & \multirow[t]{3}{*}{4.78} & \multirow[t]{3}{*}{0.091} \\
\hline High school or some college & $245(27.4)$ & $135(30.8)$ & $110(24.2)$ & & \\
\hline Up to middle school & $476(53.3)$ & $224(51.0)$ & $252(55.5)$ & & \\
\hline \multicolumn{6}{|l|}{ School period } \\
\hline Morning & $464(52.0)$ & $228(51.9)$ & $236(52.0)$ & \multirow[t]{2}{*}{0.00} & \multirow[t]{2}{*}{0.989} \\
\hline Afternoon & $429(48.0)$ & $211(48.1)$ & $218(48.0)$ & & \\
\hline \multicolumn{6}{|l|}{ BMI status } \\
\hline Normal weight & $540(61.0)$ & $267(61.8)$ & $273(60.1)$ & \multirow[t]{3}{*}{6.18} & \multirow[t]{3}{*}{0.045} \\
\hline Overweight & $228(25.7)$ & $98(22.7)^{\mathrm{a}}$ & $130(28.6)^{\mathrm{a}}$ & & \\
\hline Obesity & $118(13.3)$ & $67(15.5)$ & $51(11.3)$ & & \\
\hline \multicolumn{6}{|l|}{ Fruit consumption } \\
\hline$<3$ times per day & $711(79.6)$ & $351(79.9)$ & $360(79.3)$ & \multirow[t]{2}{*}{0.00} & \multirow[t]{2}{*}{0.951} \\
\hline$\geq 3$ times per day & $182(20.4)$ & $88(20.1)$ & $94(20.7)$ & & \\
\hline \multicolumn{6}{|l|}{ Vegetable consumption } \\
\hline$<3$ times per day & $716(80.2)$ & $365(83.1)^{\mathrm{a}}$ & $351(77.4)^{\mathrm{a}}$ & \multirow[t]{2}{*}{4.40} & \multirow[t]{2}{*}{0.035} \\
\hline$\geq 3$ times per day & $177(19.8)$ & $74(16.9)^{\mathrm{a}}$ & $102(22.6)^{\mathrm{a}}$ & & \\
\hline Mild alcohol use & & & & & \\
\hline No & $660(75.8)$ & $350(79.7)^{\mathrm{a}}$ & $327(72.0)^{\mathrm{a}}$ & 6.86 & 0.008 \\
\hline Yes & $211(24.2)$ & $89(20.3)^{a}$ & $127(28.0)^{\mathrm{a}}$ & & \\
\hline Excessive alcohol use & & & & & \\
\hline No & $754(84.4)$ & $378(86.2)$ & $375(82.6)$ & 2.17 & 0.140 \\
\hline Yes & $139(15.6)$ & $61(13.8)$ & 79 (17.4) & & \\
\hline Tobacco use & & & & & \\
\hline No & $833(93.3)$ & $414(94.2)$ & $420(92.5)$ & & \\
\hline Yes & $60(6.7)$ & $25(5.8)$ & $34(7.5)$ & 0.97 & 0.323 \\
\hline
\end{tabular}

$\mathrm{SD}=$ standard deviation; $\mathrm{t}=$ independent $\mathrm{t}$ test $\mathrm{MVPA}=$ moderate to vigorous physical activity; $\chi^{2}=$ Chi-square test; $\mathrm{BMI}=$ body mass index; aIndicates significant differences between sex. 
Table 2 shows the associations between MVPA and fruit and vegetable consumption. Participants with moderate and high MVPA were less likely to report low fruit consumption in the unadjusted model for overall, in-school, and out-of-school MVPA.

The associations between high MVPA and low fruit consumption remained significant after adjustments (model 2) for overall MVPA (moderate: OR $=0.58$; 95CI\%: 0.34-0.99, high: $\mathrm{OR}=0.30 ; 95 \% \mathrm{CI}$ : 0.18-0.51), in-school MVPA (moderate: $\mathrm{OR}=0.60$; 95\%CI: 0.39-0.93, high: OR =0.38; 95\%CI: $0.18-$ 0.79 ), and out-of-school MVPA (moderate: OR = 0.58; 95\%CI: 0.38-0.88, high: $\mathrm{OR}=0.34 ; 95 \% \mathrm{CI}$ : $0.22-0.51)$. The associations between high MVPA and low vegetable consumption remained significant in the adjusted model 2 for in-school MVPA (OR = 0.43; 95\%CI: 0.25-0.73).

Table 3 shows the associations between MVPA and alcohol and tobacco use. The unadjusted model indicated that mild alcohol use and excessive alcohol use were inversely associated with in-school and weekend MVPA with OR ranging from 0.35 (95\%CI: 0.17-0.72) to 0.76 (95\%CI: 0.59-0.99). Out of school MVPA was positively associated with excessive alcohol use $(\mathrm{OR}=1.60 ; 95 \% \mathrm{CI}: 1.18-2.29)$. Participants with high in-school MVPA were less likely to report tobacco use $(\mathrm{OR}=0.42$; 95\%CI: 0.24-0.74).

Adjustments made in Model 2 resulted in a different pattern of results for alcohol use in comparison to the unadjusted model. Some associations became non-significant after adjustment (in-school MVPA and mild alcohol use; in-school MVPA and excessive alcohol use; and weekend MVPA and excessive alcohol use). However, a number of other associations became significant after adjustments (moderate overall MVPA and mild alcohol use: $\mathrm{OR}=1.57 ; 95 \% \mathrm{CI}$ : 1.10-2.32; high overall MVPA and mild alcohol use: $\mathrm{OR}=1.54$; 95\%CI: 1.08-2.19; moderate overall MVPA and excessive alcohol use: $\mathrm{OR}=1.97 ; 95 \% \mathrm{CI}$ : 1.28-3.03; and high overall MVPA and excessive alcohol use: OR = 1.53; 95\%CI: 1.01-2.33). Interestingly, one association changed direction after adjustment (moderate weekend MVPA and mild alcohol use: $\mathrm{OR}=1.61 ; 95 \% \mathrm{CI}$ : 1.10-2.36). Regarding tobacco use, association seen for in-school MVPA remained significant in the adjusted model 2 (OR= 0.52; 95\%CI: 0.29-0.89).

The combined analyses examining both $\mathrm{PA}$ and $\mathrm{SB}$ yielded some interesting interactions (Figure 1). Participants with moderate and high MVPA at any level of SB were significantly less likely to report low fruit

Table 2 - Odds ratio (OR) and 95\% confidence interval (95\% CI) for associations among physical activity, fruit and vegetable consumption in Brazilian adolescents

\begin{tabular}{|c|c|c|c|c|c|c|c|c|}
\hline & \multicolumn{4}{|c|}{ Fruit consumption (< 3 times/day $)$} & \multicolumn{4}{|c|}{ Vegetable consumption (< 3 times/day) } \\
\hline & & & Model 1 & Model 2 & & & Model 1 & Model 2 \\
\hline & $\mathrm{n}$ & $\%$ & OR $(95 \% \mathrm{CI})$ & OR $(95 \% \mathrm{CI})$ & $\mathrm{n}$ & $\%$ & OR $(95 \% \mathrm{CI})$ & OR $(95 \% \mathrm{CI})$ \\
\hline \multicolumn{9}{|l|}{ Overall MVPA } \\
\hline Low MVPA & 262 & 88.8 & 1 & 1 & 255 & 84.1 & 1 & 1 \\
\hline Moderate MVPA & 241 & 81.7 & $0.55(0.32-0.90)^{*}$ & $0.58(0.34-0.99)^{*}$ & 255 & 84.4 & $0.90(0.42-1.90)$ & $1.07(0.42-2.71)$ \\
\hline High MVPA & 207 & 68.5 & $0.28(0.17-0.45)^{* *}$ & $0.30(0.18-0.51)^{* *}$ & 214 & 70.6 & $0.40(0.20-0.81)^{*}$ & $0.49(0.22-1.09)$ \\
\hline \multicolumn{9}{|l|}{ In-school MVPA } \\
\hline Low MVPA & 258 & 86.9 & 1 & 1 & 263 & 86.8 & 1 & 1 \\
\hline Moderate MVPA & 239 & 79.7 & $0.63(0.31-0.96)^{*}$ & $0.60(0.39-0.93)^{*}$ & 245 & 80.8 & $0.76(0.46-1.24)$ & $0.74(0.45-1.23)$ \\
\hline High MVPA & 213 & 72.2 & $0.38(0.18-0.75)^{* * *}$ & $0.38(0.18-0.79)^{*}$ & 216 & 71.5 & $0.39(0.23-065)^{* * *}$ & $0.43(0.25-0.73)^{* * *}$ \\
\hline \multicolumn{9}{|l|}{ Out-of-school MVPA } \\
\hline Low MVPA & 254 & 87.9 & 1 & 1 & 253 & 83.2 & 1 & 1 \\
\hline Moderate MVPA & 242 & 81.7 & $0.54(0.35-0.85)^{* *}$ & $0.58(0.38-0.88)^{*}$ & 248 & 82.9 & $0.87(0.53-1.42)$ & $0.98(0.57-1.97)$ \\
\hline High MVPA & 214 & 69.7 & $0.30(0.20-0.43)^{* * *}$ & $0.34(0.22-0.51)^{* *}$ & 224 & 73.2 & $0.49(0.29-0.83)^{* *}$ & $0.58(0.32-1.03)$ \\
\hline \multicolumn{9}{|l|}{ Weekend MVPA } \\
\hline Low MVPA & 252 & 84.3 & 1 & 1 & 257 & 85.1 & 1 & 1 \\
\hline Moderate MVPA & 240 & 80.8 & $0.83(0.52-1.32)$ & $1.10(0.66-1.83)$ & 243 & 81.0 & $0.79(0.50-1.26)$ & $1.28(0.67-2.44)$ \\
\hline High MVPA & 218 & 73.6 & $0.53(0.35-0.80)^{* * *}$ & $0.69(0.47-1.00)$ & 225 & 73.3 & $0.50(0.34-0.73)^{* *}$ & $0.76(0.52-1.11)$ \\
\hline
\end{tabular}

Model 1 = crude association; Model 2 = controlled by gender, age, BMI status, socioeconomic status, parent educational level, school period and sedentary behavior; MVPA = moderate to vigorous physical activity; ${ }^{*} \mathrm{p}<0.05 ;{ }^{* *} \mathrm{p}<0.01$. 
Table 3 - Odds ratio (OR) and 95\% confidence interval (95\% CI) for associations among physical activity, mild, excessive alcohol use and tobacco use in Brazilian adolescents

\begin{tabular}{|c|c|c|c|c|c|c|c|c|c|c|c|c|}
\hline & \multicolumn{4}{|c|}{$\begin{array}{l}\text { Mild alcohol use } \\
\text { (at least one time on the past } 30 \text { days) }\end{array}$} & \multicolumn{4}{|c|}{$\begin{array}{c}\text { Excessive alcohol use } \\
\quad \text { ( } 5 \text { or more doses) } \\
\text { (at least one time on the past } 30 \text { days) }\end{array}$} & \multicolumn{4}{|c|}{$\begin{array}{c}\text { Tobacco use } \\
\text { (at least one time in the past } 30 \text { days) }\end{array}$} \\
\hline & & & Model 1 & Model 2 & & & Model 1 & Model 2 & & & Model 1 & Model 2 \\
\hline & $\mathrm{n}$ & $\%$ & $\begin{array}{c}\text { OR } \\
(95 \% \mathrm{CI})\end{array}$ & $\begin{array}{c}\text { OR } \\
(95 \% \mathrm{CI})\end{array}$ & $\mathrm{n}$ & $\%$ & $\begin{array}{c}\text { OR } \\
(95 \% \mathrm{CI})\end{array}$ & $\begin{array}{c}\text { OR } \\
(95 \% \mathrm{CI})\end{array}$ & $\mathrm{n}$ & $\%$ & $\begin{array}{c}\text { OR } \\
(95 \% \mathrm{CI})\end{array}$ & $\begin{array}{c}\text { OR } \\
(95 \% \mathrm{CI})\end{array}$ \\
\hline \multicolumn{13}{|l|}{ Overall MVPA } \\
\hline Low MVPA & 71 & 23.7 & 1 & 1 & 41 & 13.7 & 1 & 1 & 20 & 6.7 & 1 & 1 \\
\hline Moderate MVPA & 83 & 27.8 & $\begin{array}{c}1.15 \\
(0.84-1.57)\end{array}$ & $\begin{array}{c}1.57 \\
(1.10-2.32)^{*}\end{array}$ & 62 & 20.9 & $\begin{array}{c}1.41 \\
(0.92-2.16)\end{array}$ & $\begin{array}{c}1.97 \\
(1.28-3.03)^{* *}\end{array}$ & 25 & 8.4 & $\begin{array}{c}1.20 \\
(0.62-2.35)\end{array}$ & $\begin{array}{c}1.170 \\
(0.48-2.87)\end{array}$ \\
\hline High MVPA & 62 & 20.8 & $\begin{array}{c}0.78 \\
(0.50-1.21)\end{array}$ & $\begin{array}{c}1.54 \\
(1.02-2.19)^{*}\end{array}$ & 37 & 12.4 & $\begin{array}{c}0.79 \\
(0.58-1.09)\end{array}$ & $\begin{array}{c}1.53 \\
(1.01-2.33)^{*}\end{array}$ & 15 & 5.0 & $\begin{array}{c}0.73 \\
(0.35-1.54)\end{array}$ & $\begin{array}{c}0.95 \\
(0.32-2.80)\end{array}$ \\
\hline \multicolumn{13}{|l|}{ In-school MVPA } \\
\hline Low MVPA & 91 & 30.5 & 1 & 1 & 64 & 21.5 & 1 & 1 & 24 & 8.0 & 1 & 1 \\
\hline Moderate MVPA & 77 & 25.7 & $\begin{array}{c}0.76 \\
(0.59-0.99)^{*}\end{array}$ & $\begin{array}{c}1.03 \\
(0.74-1.43)\end{array}$ & 48 & 16.0 & $\begin{array}{c}0.60 \\
(0.42-0.86)^{* *}\end{array}$ & $\begin{array}{c}0.78 \\
(0.52-1.17)\end{array}$ & 25 & 8.3 & $\begin{array}{c}1.04 \\
(0.61-1.76)\end{array}$ & $\begin{array}{c}1.16 \\
(0.68-1.96)\end{array}$ \\
\hline High MVPA & 48 & 16.1 & $\begin{array}{c}0.44 \\
(0.24-0.81)^{* *}\end{array}$ & $\begin{array}{c}0.83 \\
(0.53-1.30)\end{array}$ & 28 & 9.4 & $\begin{array}{c}0.35 \\
(0.17-0.72)^{* *}\end{array}$ & $\begin{array}{c}0.63 \\
(0.33-1.22)\end{array}$ & 11 & 3.7 & $\begin{array}{c}0.42 \\
(0.24-0.74)^{* *}\end{array}$ & $\begin{array}{c}0.52 \\
(0.29-0.89)^{* * *}\end{array}$ \\
\hline \multicolumn{13}{|l|}{ Out-of-school MVPA } \\
\hline Low MVPA & 62 & 20.7 & 1 & 1 & 36 & 12.0 & 1 & 1 & 18 & 6.0 & 1 & 1 \\
\hline Moderate MVPA & 83 & 27.9 & $\begin{array}{c}1.22 \\
(0.85-1.74)\end{array}$ & $\begin{array}{c}1.60 \\
(1.18-2.29)^{*}\end{array}$ & 52 & 17.5 & $\begin{array}{c}1.24 \\
(0.77-1.99)\end{array}$ & $\begin{array}{c}1.74 \\
(0.95-3.16)\end{array}$ & 20 & 6.8 & $\begin{array}{c}0.93 \\
(0.52-1.66)\end{array}$ & $\begin{array}{c}1.09 \\
(0.63-1.89)\end{array}$ \\
\hline High MVPA & 71 & 23.7 & $\begin{array}{c}1.06 \\
(0.76-1.49)\end{array}$ & $\begin{array}{c}1.45 \\
(0.91-2.32)\end{array}$ & 52 & 17.3 & $\begin{array}{c}1.34 \\
(1.02-1.76)^{*}\end{array}$ & $\begin{array}{c}1.91 \\
(1.15-3.28)^{*}\end{array}$ & 22 & 7.3 & $\begin{array}{c}1.34 \\
(0.61-2.96)\end{array}$ & $\begin{array}{c}1.56 \\
(0.55-4.45)\end{array}$ \\
\hline \multicolumn{13}{|l|}{ Weekend MVPA } \\
\hline Low MVPA & 87 & 29.1 & 1 & 1 & 60 & 20.1 & 1 & 1 & 27 & 9.0 & 1 & 1 \\
\hline Moderate MVPA & 64 & 21.5 & $\begin{array}{c}0.65 \\
(0.45-0.94)^{*}\end{array}$ & $\begin{array}{c}1.61 \\
(1.10-2.36)^{*}\end{array}$ & 41 & 13.8 & $\begin{array}{c}0.57 \\
(0.42-0.75)^{* *}\end{array}$ & $\begin{array}{c}1.34 \\
(.93-1.94)\end{array}$ & 16 & 5.4 & $\begin{array}{c}0.55 \\
(0.23-1.30)\end{array}$ & $\begin{array}{c}1.36 \\
(0.62-2.97)\end{array}$ \\
\hline High MVPA & 65 & 21.6 & $\begin{array}{c}0.61 \\
(0.33-1.14)\end{array}$ & $\begin{array}{c}1.88 \\
(1.28-2.77)^{* * *}\end{array}$ & 39 & 13.0 & $\begin{array}{c}0.51 \\
(0.33-0.78)^{* *}\end{array}$ & $\begin{array}{c}1.51 \\
(0.80-2.83)\end{array}$ & 17 & 5.7 & $\begin{array}{c}0.41 \\
(0.15-1.08)\end{array}$ & $\begin{array}{c}1.14 \\
(0.47-2.77)\end{array}$ \\
\hline
\end{tabular}

Model 1 = crude association; Model 2 = controlled by gender, age, BMI status, socioeconomic status, parent educational level, school period and Sedentary Behavior; MVPA = moderate to vigorous physical activity; ${ }^{*} \mathrm{p}<0.05 ;{ }^{* *} \mathrm{p}<0.01$.

consumption than participants in the low MVPA and high SB group. The odds ratios for fruit consumption ranged from 0.25 (high MVPA and low SB group) to 0.54 (moderate MVPA and low SB group) - Figure 1a. The combination of PA and SB also led to interactions with alcohol. Participants with moderate MVPA and high $\mathrm{SB}(\mathrm{OR}=1.91 ; 95 \% \mathrm{CI}: 1.14-3.22)$, moderate MVPA and low SB (OR = 2.30; 95\%CI: 1.35-3.92), and high MVPA and high SB $(\mathrm{OR}=2.79 ; 95 \% \mathrm{CI}$ : 1.52-5.12) were significantly more likely to report mild alcohol use than adolescents with ow MVPA and high SB (Figure 1b). In addition, participants in all combinations of MVPA and SB were significantly more likely to report excessive alcohol use (Figure 1c.) than the low MVPA and high SB group. The odds ratios for excessive alcohol use ranged from 2.94 (high MVPA and high SB) to 4.75 (moderate MVPA and low SB).

\section{Discussion}

Poor diet, alcohol and tobacco use, low levels of PA and high levels of SB are related to obesity and cardiometabolic risk factors ${ }^{2-5}$, and their prevalence is high among adolescents ${ }^{18}$. This study found alarmingly low rates of fruit and vegetable consumption (over 70\%), and high rates of alcohol (mild: 24.0\%; excessive: 15.6\%) and tobacco use (6.7\%). Many factors influence the adoption of healthy behaviors, but the importance of PA to the adoption of other healthy behaviors has been equivocal, if not contradictory in previous studies ${ }^{10-17}$. The present study provides new insights into the associations between PA and various health risk behaviors in a sample of adolescents from a metropolitan city in Southern Brazil.

Participation in MVPA may encourage adolescents to consume more fruits and vegetables. Lowry et al. ${ }^{9}$ indicated that adolescents who engaged in at least 60 

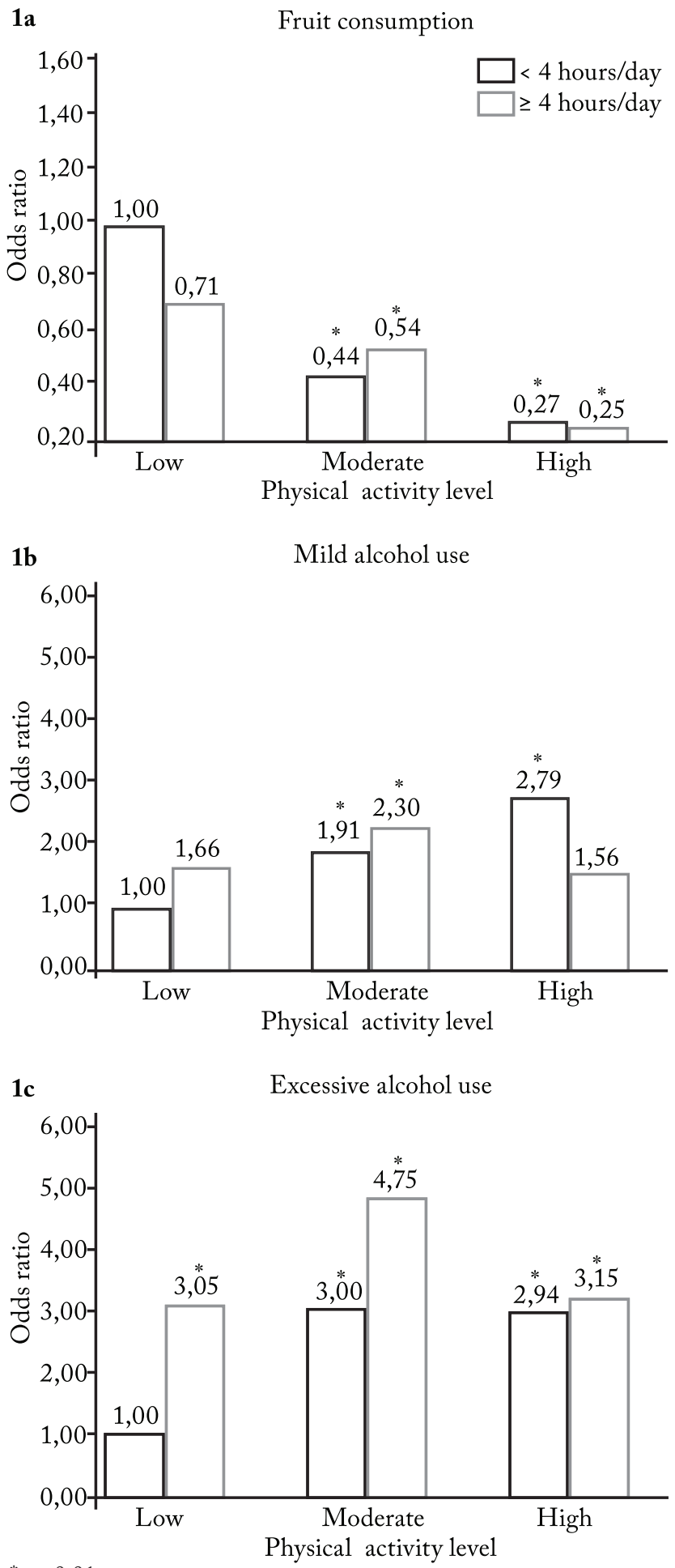

*p $\leq 0.01$

Figure 1 - Odds ratio (OR) for interactions between Overall MVPA and SB with health risk behaviors in Brazilian adolescents

minutes of daily MVPA were more likely to eat fruits and vegetables at least 3 times a day. Silva et al. ${ }^{11}$ found that less active Brazilian boys were more likely to report low fruit and vegetable consumption. Similarly, our results showed that active adolescents had higher consumption of fruits. This may be explained by the fact that more active individuals may be more conscious of (or motivated toward) better eating habits ${ }^{24,25}$. Our results also showed that FV consumption was particularly associated with in-school physical activity. Adolescents with higher levels of in-school MVPA were more likely to report the consumption of $\mathrm{FV}$ at least 3 times per day. The structure of physical education classes in Brazil might explain the importance of in-school physical activity to the consumption of FV in our sample. Physical education classes are compulsory in the Brazilian educational system. In addition to providing opportunities for physical activity ${ }^{26}$, federal law mandates that middle and high-school physical education classes encourage the adoption of healthy habits.

Tobacco use has several detrimental health consequences and commonly starts during adolescence. Being a smoker during adolescence greatly increases the continuation of this behavior during adult life $\mathrm{e}^{15}$. The association between MVPA and tobacco use may vary according to population characteristics and types or contexts of PA ${ }^{10,14,27}$. Overall levels of MVPA do not seem to protect adolescents against the likelihood of smoking. Our findings were similar to the results from eight African countries ${ }^{17}$, and they indicated that overall MVPA was not associated with tobacco use. In fact, there is even evidence pointing to higher likelihood of smoking for more active American Hispanic adolescents $^{10}$. On the other hand, engaging in PA in school settings may assist adolescents stray away from smoking. Brazilian adolescents with high in-school MVPA levels were less likely to report tobacco use. High participation in in-school PA was also associated with lower tobacco use in a sample of American adolescents ${ }^{27}$. As shown for FV consumption, physical education classes might have positive impacts on reducing the prevalence of unhealthy behaviors among adolescents. While causality cannot be assumed, promoting opportunities for adolescents to be more active in school settings may contribute to lower likelihood of smoking.

Alcohol use is related to several social problems, and it contributes substantially for the global burden of disease $\mathrm{e}^{28}$. The literature shows contradictory evidence about the association of PA and alcohol use in adolescents with some studies indicating a direct ${ }^{10,17}$, while others an inverse ${ }^{27}$ or a lack of association ${ }^{15}$. Our results indicated that overall PA (moderate and high MVPA) was positively associated with mild and excessive alcohol use. Our results show that the context of 
PA may influence alcohol behavior in different ways. Out-of-school MVPA was positively associated with both mild alcohol use (moderate MVPA) and excessive alcohol use (high MVPA) while weekend MVPA was positively associated with mild alcohol use. PA performed outside of school settings may stimulate social interactions with peers of the same age group. In addition, social interactions during PA performed outside of school may be more unstructured and unsupervised than social interactions occurring in school settings. Social interactions with peers play an important role in shaping use of alcohol and engagement of PA by adolescents ${ }^{29}$. Thus, the social dynamic of PA in settings outside of schools may contribute to increased alcohol use during adolescence.

Sedentary behavior is also a key predictor of health risk behaviors in adolescents ${ }^{10,11,13,16,17}$, but the interaction between PA and SB in the prediction of unhealthy behaviors has not been systematically evaluated. Previous evidence suggests that decreasing the screen time favors the adoption of healthy eating behaviors in adolescents ${ }^{9}$. Our results further suggest that higher MVPA levels were associated with higher fruit consumption irrespective of SB. Thus, strategies to increase MVPA levels in adolescents may contribute to adoption of healthier eating patterns.

Based on the interaction between $\mathrm{PA}$ and $\mathrm{SB}$, increasing levels of MVPA or lowering SB were associated with higher rates of mild and excessive alcohol use by brazilian adolescents. These results highlight the importance of considering SB when using PA to predict mild and excessive use of alcohol among adolescents. In fact, even adolescents in the group with low MVPA and low SB were $\sim 3$ times more likely to report excessive alcohol use than those in the low MVPA and high SB. Increasing PA participation and reducing SB time are common health recommendations for adolescents. However, the association of these behaviors with alcohol use suggests the implementation of compensatory strategies for possible increases in SB not to overshadow the benefits of a more active lifestyle.

This study is not without limitations. Self-reported data on PA and SB time may be susceptible to social desirability and other forms of bias. The recall of health risk behaviors followed procedures commonly used in previous surveys, but it was limited to the previous 7 days prior to data collection for fruit and vegetable consumption and 30 days for alcohol and tobacco use. There are also several important strengths to this study.
Participants were from a randomly selected sample of public schools. The measure of PA provided information about the specific contribution of PA context (in-school, out-of-school and weekend) to the prediction of health risk behaviors. Finally, this was the first study examining the interaction between PA and SB in the prediction of other health risk behaviors in brazilian adolescents.

The findings of this study indicate that physical activity may play a protective role against health risk behaviors in adolescence. Adolescents who were more physically active tended to consume more fruits, vegetables and less tobacco. That may be particularly true for in-school PA. Our results regarding associations between in-school MVPA, fruit and vegetable consumption and tobacco use indicate the importance of school policies to enhance health behaviors of adolescent students. Promoting active lifestyles in school can influence the adoption of other health behaviors. In-school PA is mostly delegated to physical education. Physical education classes are mandatory at least twice per week in middle and high school levels in Brazil, and they may stimulate the adoption of healthier lifestyles by exposing adolescents to structured PA and knowledge about healthy nutrition and smoking avoidance. We recommend that schools expand PA promotion initiates to further increase adolescents' adoption of overall healthy lifestyle. In addition to increasing physical education offerings, more opportunities for PA can be provided during recess, in afterschool programs, and in the form of PA brain breaks during classroom instruction.

On the other hand, PA occurring outside of the school (week and weekend days) was related to alcohol use. Adolescents with higher MVPA levels outside of school were more likely to report both mild and excessive alcohol use. Out-of-school week and weekend MVPA commonly occur in the form of participation in sport practices. Engagement in sports may increase the likelihood of alcohol use during adolescence due the several factors such as peer norms, bonding, and initiation rituals ${ }^{30}$. Coaches may be key figures to curb the use of alcohol by adolescents heavily involved in PA outside of school. We recommend for coaches to model positive behaviors, prohibit initiation rituals that are alcohol conducive, and educate athletes and parents about the negative effects of alcohol use during adolescence.

The associations between PA and screen time with alcohol use point to the complex relationships among social and cultural influences on behavior. However, it is important to note that the results presented here are 
cross sectional. Efforts to promote physical activity may not lead to corresponding adoption of alcohol use since the social and cultural contexts may be entirely different. Nonetheless, school officials and physical education teachers should both work together to educate adolescents about the importance of healthy lifestyle choices. They should particularly warn adolescents about the risks of peer pressure to drink alcohol that may arise during participation in physical activity outside of school.

\section{Conflict of interest}

The authors declare no conflict of interest.

\section{Author's contributions}

Silva MP, participated in the initial study concept, data collection and analysis, writing and critical review of the manuscript. Fontana FE, Welk GJ, Saint-Maurice PF and Campos W, participated in the initial study concept, writing and critical review of the manuscript. Fantineli ER, participated the data collection and critical review of the manuscript. Bacil EDA, participated in the critical review of the manuscript.

\section{Acknowledgments}

The authors thank the Conselho Nacional de Desenvolvimento Científico e Tecnológico (CNPq) for the support to develop this work through the doctoral sandwich program.

\section{References}

1. Straatmann VS, Oliveira AJ, Rostila M, Lopes CS. Changes in physical activity and screen time related to psychological well-being in early adolescence: findings from longitudinal study ELANA. BMC Public Health. 2016;16(1):977.

2. Stamatakis E, Coombs N, Tiling K, Mattocks C, Cooper A, Hardy LL, et al. Sedentary time in late childhood and cardiometabolic risk in adolescence. Pediatrics. 2015;135(6):e1432-e1441.

3. Du H, Li L, Bennett D, Guo Y, Tumbull I, Yang L, et al. Fresh fruit consumption in relation to incident diabetes and diabetic vascular complications: A 7-y prospective study of 0.5 million Chinese adults. PLoS Med.2017;14(4):e1002279.

4. Spring B, Moller AC, Coons MJ. Multiple health behaviours: overview and implications. J Public Health (Oxf). 2012;34,Suppl 1:i3-10.

5. Meyer U, Schindler C, Bloesch T, Schmocker E, Zahner L, Puder JJ, et al. Combined impact of negative lifestyle factors on cardiovascular risk in children: a randomized prospective study. J Adolesc Health. 2014;55(6):790-95.

6. Marshall SJ, Biddle SJH, Gorely T, Cameron N, Murdey I. Relationships between media use, body fatness and physical activity in children and youth: A meta-analysis. Int J Obes. 2004;28(10):1238-46.

7. Ekelund U, Luan J, Sherar LB, Esliger DW, Griew P, Cooper A. Association of moderate to vigorous physical activity and sedentary time and cardiometabolic risk factors in children and adolescents. J Am Med Assoc. 2012;307(7):704-12.
8. Kim Y, Welk GJ. Characterizing the context of sedentary lifestyles in a representative sample of adults: a cross-sectional study from the physical activity measurement study project. BMC Public Health. 2015;15(1):1218.

9. Lowry R, Michael S, Demissie Z, Kann L, Galuska DA. Associations of physical activity and sedentary behaviors with dietary behaviors among us high school students. J Obes. 2015;2015:1-8.

10. Lebron C, Stoutenberg M, Janowsky M, Asfour L, Huang $\mathrm{S}$, Prado G. The role of physical activity and sedentary behavior in substance use and risky sex behaviors in hispanic adolescents. J Early Adolesc. 2017;37(7):910-24.

11. Silva FMA, Smith-Menezes A, Duarte MFS. Consumo de frutas e vegetais associado a outros comportamentos de risco em adolescentes no Nordeste do Brasil. Rev Paul Pediatr. 2016;34(3):309-15.

12. Fleig L, Küper C, Lippke S, Schwarzer R, Wiedemann AU. Cross-behavior associations and multiple health behavior change: A longitudinal study on physical activity and fruit and vegetable intake. J Health Psychol. 2015;20(5):525-34.

13. Dias PJP, Domingos IP, Ferreira MG, Muraro AP, Sichieri $\mathrm{R}$, Gonçalves-Silva RMV. Prevalence and factors associated with sedentary behavior in adolescents. Rev Saude Publica. 2014;48(2):266-74.

14. Charilaou M, Karekla M, Constantinou M, Price S. Relationship between physical activity and type of smoking behavior among adolescents and young adults in Cyprus. Nicotine Tob Res. 2009;11(8):969-76.

15. Paavola M, Vartiainen E, Haukkala A. Smoking, alcohol use, and physical activity: A 13-year longitudinal study ranging from adolescence into adulthood. J Adolesc Heal. 2004;35(3):238-44.

16. Lesjak V, Stanojević-Jerković O. Physical activity, sedentary behavior and substance use among adolescents in slovenian urban area. Slov J Public Heal. 2015;54(3):168-74.

17. Peltzer K. Leisure time physical activity and sedentary behavior and substance use among in-school adolescents in eight african countries. Int J Behav Med. 2010;17(4):271-78.

18. Instituto Brasileiro de Geografia e Estatística. Pesquisa Nacional de Saúde do Escolar:2015.2016:132.

19. Saint-Maurice PF, Welk GJ. Validity and calibration of the youth activity profile. Watz $\mathrm{H}$, ed. PLoS One. 2015;10(12):e0143949.

20. Guedes DP, Lopes CC. Validação da versão brasileira do Youth Risk Behavior Survey Validation of the Brazilian version of the 2007 Youth Risk Behavior Survey. Rev Saude Publica. 2010;44(5):840-50.

21. Guimarães RDF, Silva MP, Legnani E, Mazzardo O, Campos W. Reprodutibilidade de questionário de atividades sedentárias para adolescentes brasileiros. Rev Bras Cineantropom e Desempenho Hum. 2013;15(3):276-85.

22. Onis M, Onyango AW, Borghi E, Siyam A, Nishida C, Siekmann J. Development of a WHO growth reference for school-aged children and adolescents. Bull World Health Organ. 2007;85(10):812-19.

23. Associação Brasileira de Empresas de Pesquisa. Critério de Classificação Econômica Brasil. 2014. Disponível em: http:// www.abep.org/new/Servicos/DownloadCodigoConduta. aspx?id=02.

24. Ottevaere C, Huybrechts I, Benser J, De Bourdeaudhuij I, Cuenca-Garcia M, Dallongeville J, et al. Clustering patterns of physical activity, sedentary and dietary behavior among European adolescents: The HELENA study. BMC Public Health. 2011;11(1):328. 
25. Elder SJ, Roberts SB. The effects of exercise on food intake and body fatness: a summary of published studies. Nutr Rev. 2007;65(1):1-19.

26. Brasil. Parâmetros Curriculares Nacionais : Educação Física. Brasilia: MEC / SEF; 1998.

27. Nelson MC, Gordon-Larsen P.Physical activity and sedentary behavior patterns are associated with selected adolescent health risk behaviors. Pediatrics. 2006;117(4):1281-90.

28. Rehm J, Mathers C, Popova S, Thavorncharoensap M, Teerawattananon Y, Patra J. Global burden of disease and injury and economic cost attributable to alcohol use and alcohol-use disorders. Lancet. 2009;373(9682):2223-33.
29. Pechansky F, Szobot CM, Scivoletto S. Uso de álcool entre adolescentes: conceitos, características epidemiológicas e fatores etiopatogênicos. Rev Bras Psiquiatr. 2004;26(suppl 1):14-7.

30. Moore MJ, Werch CE "Chad. Sport and physical activity participation and substance use among adolescents. J Adolesc Heal. 2005;36(6):486-93.

Received: 04/12/2018

Approved: 29/04/2019

\section{Como citar este artigo:}

Silva MP, Fontana FE, Welk GJ, Saint-Maurice PF, Fantineli ER, Bacil EDA, Campos W. Associations between physical activity, sedentary behavior, and health risk behaviors among adolescents from a city in the South of Brazil. Rev Bras Ati Fis Saude. 2019;24:e068.

DOI: $10.12820 /$ rbafs.24e0068 